\title{
Impact of Emigration in Dakshinkali Municipality
}

Ram Raj Pokharel*

\begin{abstract}
Migration refers to the process of movement from one place to another, such as crossing intra or international geographical boundaries. Sociological studies of migration are diverse. The motive for migration includes political, economic, social, and environmental cause. It is a known fact that Nepali migrants are scattered around the world and many of them are in Gulf country, followed by America and Japan. This micro level study to Dakshinkali Municipality Kathmandu District. The main objectives of this study are to study the causes of migration and its socio-economic impact of the foreign employment in the study area. The total of 71 respondents was surveyed during household questionnaire survey and altogether 6 key informants were interviewed. The trend of abroad migration for foreign employment and higher education has been increasing. Among the total 71 respondents, male migrants are maximum than the female migrants with the age group of 24-29 and 30-34. The majority of people were dependent on agriculture. Despite being farmer, most of them go to the abroad for foreign employment to maintain their living standards. Remittance was mostly used for education, pay debt and other daily accommodations and only few of them invest in land and small business. High rate of wage was the main push and pull factor. In recent years, the migration has been increasing due to increased unemployment and political conflict.
\end{abstract}

Key words: Impact, emigration, push factor, pull factor, unemployment

\section{Introduction}

Migration is in an open world a 'natural' phenomenon. It is a form of geographical or spatial mobility, which involves a change of usual residence of a person between clearly defined geographical units. A person who crosses the boundary of owns country or places of country is called an out-migrant. Emigration refers to movement out of a particular territory in connection with the international migration (Bhende and Karnitkar, 1998). It is one of the three components of population change. Any change in the volume and flow of migration will change the size, growth, and other characteristics of the population both in sending and receiving areas. Migration within a country does not affect its total size of national population and growth rate but it affects regional and sub-regional population and

* Mr. Pokharel is a PhD Scholar and Assistant Professor of Sociology, Patan Multiple Campus, TU, Nepal 
growth rate within the country. Migration, inside or outside the country, affect the size and the growth of a country's population (KC, 1998).

On the basis of assumed causes influencing human movement, international migration can be broadly categorized into two groups: voluntary and involuntary (Peterson, 1978). Forced migration (e.g., refugees) calls for humanitarian aid, while voluntary migration prompts a different socio-economic challenge (Nijkamp, 2012). People are moving from one place to another since ancient period, which is a continuous international phenomenon resulted due to complex mechanism, involving social, economic, psychological, political, institutional and other determinants (Singh, 1998).

Migration unlike fertility and mortality is the least researched and understood component of demographic dynamics in Nepal despite the fact that many of Nepal's socio-economic and political problems are interwoven with the process of both internal and international migration (KC, 1998). However, if we look through the present time, migration is the most chosen topic for the research which denotes it is the most concerned aspect of demography. The current situation of population in Nepal results in part from both emigration and immigration. Historically, three forms of emigration are evident: a) movement related to military recruitment, b) Movement for agricultural and other economic activities, and c) marriage migration. More than 90 percent of all emigrants are from Hills and Mountains of Nepal (Subedi, 1991).

Nepal has a long history of international labor migration. Nepal had been a country of destination for immigrants from both north and south. The history of formal entrance of Nepalese citizens in foreign employment begins in 1814- 1815 after the Nepal-British India war. A total of 4,650 Nepalese youngsters were recruited to the British armed forces as a British-Gurkha regiment (Bhattarai, 2005). Similarly, the migration of Nepalese people for other employment purpose begins to work in the tea estates of Darjeeling and forest of Assam by the second half of the 19th century. Economic migration to the Middle East from South Asia and other parts of the world was spurred-on by the oil boom in the early 1970s. The reasons behind the migration are almost same in Nepal as other parts of the world. Existing poverty, limited employment opportunities, deteriorating agricultural productivity, armed conflict are some of the reasons about the motives behind international migration. There are many villages in Nepal where the migration has been established as a culture of community to go aboard for work for a while and return back with some money and experience of placement in different geographical location. The influence of friends, relatives and well-wishers has also played a prominent role to the promotion of international migration (Bhattarai, 2005). In recent year, remittance emerged as one of the premier sources of foreign exchange through foreign employment that will have significant 
bearing on the economic development of Nepal, especially in the context of poverty alleviation (Shrestha, 2004).

Dakshinkali municipality is the one of the historical settlement which is also not free from the activity of migration and facing various impacts positive as well as negative impacts of migration.

From the study of Dakshinkali municipality, it can be hoped to find out the causes of migration and advantages and disadvantages created by migration, which is the main purpose of the study. Besides, the problems of migration, reasons for the migration and the influence of migration on the lives of locals are the other parts of the study and also hoped to find out much more facts.

\subsection{General Introduction of the Study Area}

Dakshinkali municipality of Kathmandu district is one of the historical located in Kathmandu district. It is one of the settlements of different caste/ethnic people are inhabitants. Most of the people of this area are in abroad due to the social, economic and educational reason. It has been increasing since last few years, which is one of the most sensational issue of Nepalese context. Therefore, I have selected this Dakshinkali municipality for the research. Since, this study tried to find out the causes and consequences of migration on socio- economic status of the people.

\section{Objectives}

The overall objective of this study is to find out the facts and figures relating to the people and their socio cultural lives of Dakshinkali municipality. Whereas the specific objectives of the study are to find out the causes of migration and the various positive and negative impacts to the study area caused by the migration.

\section{Methodology}

This article is prepared by using primary data, collected from household questionnaire survey, key informant interview and secondary data were taken from previous studies, published books and other related literature.

\section{Sampling procedure}

The research is based on Dakshinkali municipality of Kathmandu district. Those people who have gone for foreign employment for at least 1 year were taken as respondents. There are altogether 347 people have been in abroad for different reason (Municipality profile, 2076). Among them 71 respondents (20\% of total migrants) were selected from 9 wards. Hence, for this research, 347 migrants are the universe while the 71 respondents are the 
samples. The samples were chosen through the stratified random sampling, in which each ward was considered as one strata. The sample size across wards is given in Table 1.

Table 1: Sample size

\begin{tabular}{|l|l|l|}
\hline Wards & Total Migrants (N) & Sample Size (Ss) \\
\hline 1 & 60 & 13 \\
\hline 2 & 49 & 10 \\
\hline 3 & 22 & 4 \\
\hline 4 & 10 & 2 \\
\hline 5 & 33 & 6 \\
\hline 6 & 10 & 2 \\
\hline 7 & 30 & 6 \\
\hline 8 & 82 & 17 \\
\hline 9 & 51 & 11 \\
\hline Total & 347 & 71 \\
\hline & & \\
\hline
\end{tabular}

\section{Discussion and Analysis of the study}

\subsection{Causes of Migration}

Migration is one of the third components of population change. Any change in the volume and flow of migration will change the size, growth, and other characteristics of the population both in sending and receiving areas. Migration within a country does not affect its total size of the population and growth rate but it affects regional and sub-regional population and growth rate within the country.

It is a global phenomenon caused not only by economic factors, but also by social, political, cultural, environmental, health, education and transportation factors. It commonly takes place because of the push factors of fewer opportunities in the socio-economic situation and also because of pull factors that exist in more developed areas.

\subsubsection{Push Factor}

The push factors are factors that compel a person, due to different reasons, to leave that place and go to some other place. There are various reasons behind migration. The common 
push factors were unemployment, poor economic conditions, education and present political situation.

Table 2: Push factors (associated with origin)

\begin{tabular}{|l|l|l|}
\hline Push Factor & Frequency & Percent \\
\hline Poor economic condition & 2 & 2.8 \\
\hline Present political situation & 4 & 5.6 \\
\hline Unemployment & 37 & 52.1 \\
\hline Education & 28 & 39.4 \\
\hline Total & 71 & 100.0 \\
\hline
\end{tabular}

Source: Field Survey, 2020

Economic factors are the main motivation behind migration. 2.8\% people compelled to go to abroad for foreign employment to enhance their economic condition. According to the International Labor Organization, approximately half of the total population of international migrants has left their home to find better job and lifestyle opportunities for their families. Most of the people are dependent on subsistence agriculture but production is barely sufficient to meet domestic consumption needs. Each and every household are facing difficulties to maintain their livelihood as a result the proportion of foreign migrants has increased. Therefore, foreign employment has become the main source of income for the people of the Dakshinkali Municipality in general. Thus, international migration has remained as a support for the livelihood in the study area.

Similarly, other reported push factor was present political situation of our country by $5.6 \%$ of people. Due to the political instability, development process is being backward, they feel unsafe for future life and trying for foreign employment. The people are willing to earn money from foreign employment for bright future.

Unemployment was the main cause of migration in Dakshinkali municipality. Almost half of the migrants i.e. $52.1 \%$ from the study area forced to go to abroad to get opportunity of foreign employment for the improvement of their livelihood. Unemployment is a serious one and it leads to a number of consequences like disorganization in social relationship, family and individual themselves. An unemployment people loss their self-respect and disappointing outlook. Thus it is one of the highest push factor associated with the foreign employment. Very high unemployment and underemployment rates of 17.4 and 32.3 per cent (NPC, 2003) have compelled people to remain either under severe poverty or migrate to other places within and outside the country for better opportunity for livelihood. In the 
study area, the number of migrant are increasing day by day, $4.61 \%$ of total population of the study area was involved in foreign employment (municipality profile, 2076). Different employment opportunities in international country are the root cause of migration and compelled youth to go abroad for employment.

After unemployment, 39.4\% of locals went to abroad for their higher education. In context of Nepal, there is no proper systems where the students can continue their study with doing their own job. The people reported that they could not continue for further study due to economic problem and push them to go abroad for higher education by doing work. In addition, through this, they can improve an economic status of their family too.

\subsubsection{Pull Factors}

Pull factors refer to the factors that encourage migration such as employment opportunities and other economic opportunities. Opportunities for better employment, higher wages rate, good quality of education, social relationship and easy availability attracted the people in the certain country. The migrated people reported several reasons for choosing destination country. The Table 3 shows the pull factors as causes of the emigration.

Table 3: Pull Factors (Associated with Destination)

\begin{tabular}{|l|l|l|}
\hline Pull Factors & Frequency & Percent \\
\hline Easy entry and exit & 17 & 23.9 \\
\hline Reference of friends/ relatives & 2 & 2.8 \\
\hline Higher wage rate & 23 & 32.4 \\
\hline Education (Good quality) & 19 & 26.8 \\
\hline Others & 10 & 14.1 \\
\hline Total & 71 & 100.0 \\
\hline
\end{tabular}

Source: Field Survey, 2020

The flow of foreign employment in Dakshinkali municipality was towards Gulf States. Visa and work permit are compulsory in these countries but manpower companies work as mediator between migrants and destination. So it is easy to go to Gulf country. In this study, $23.9 \%$ of the total people reported that rules to easy entry and exit as reason associated with the destination.

The friends and relatives are the main source of information for the migrants. Once their friends go to one place they send information to their non-migrant friends and influence them to go there. $2.8 \%$ of the total respondents reported that their main cause of migration was due to their relatives and friends. Generally, migrants like to have their friends and relatives around them so they can get the necessary help from them during transition period. 
$32.4 \%$ of the total respondent reported that the higher wage rate was the main factor associated with migration. It has generally been accepted that the destination of net migration is away from low wage region towards high wage ones (Subedi, 1991). People moving to more developed countries will often find that the same work they were doing at home is rewarded abroad with higher wages. They will also find a greater safety net of welfare benefits should they be unable to work. Migrants are drawn to those countries where they can maximize benefits.

Education has direct impact on the development of a person and society of a nation. In any society, where there is no education; ignorance and superstition dominates and possibilities of development become bleak. Good education is the first step towards leading individuals and society towards creative thinking and development. Lack of good education and the job regarding their qualification in our country Nepal is the main cause of emigration towards foreign country. $26.8 \%$ people of Dakshinkali Municipality went to abroad for good quality of education as well as the opportunity to secure their future.

\subsubsection{Destination Country}

The migrants from Dakshinkali Municipality have gone to different countries for higher education and employment. Australia, Dubai, India, Japan, Qatar, Saudi Arab, U. K., and U.S.A. were the main destination of the migrants. The largest no. of migrants has gone to Gulf countries: Saudi Arabia (14.1\%) and Qatar (19.7\%). It seems that the Gulf countries have become the ultimate destination of foreign employments. Similarly, Japan and United State of America were also the most frequently selected countries by migrants usually for their higher education as well as employment. Few percent (5.6\%) of people from Dakshinkali Municipality have gone to U.K. It seems that those from economically poor background and without any forms of personal connection and networks can only afford to go to the Gulf countries because of lower cost and legal procedure.

Table 4: Destination of Migrants

\begin{tabular}{|l|l|l|}
\hline Name of Country & Frequency & Percent \\
\hline Australia & 8 & 11.3 \\
\hline Dubai & 8 & 11.3 \\
\hline India & 7 & 9.9 \\
\hline Japan & 10 & 14.1 \\
\hline Qatar & 14 & 19.7 \\
\hline Saudi Arab & 10 & 14.1 \\
\hline U.K. & 4 & 5.6 \\
\hline U.S.A. & 10 & 14.1 \\
\hline Total & 71 & 100.0 \\
\hline
\end{tabular}

Source: Field Survey, 2020 


\subsubsection{Jobs in abroad}

Generally, Nepali labor migrants have to be involved in 3D work (Dirty, Danger, Difficulty) abroad because of the lack of skill and low level of education. The migrants from the study area were involved in various types of the jobs.

Table 5: Distribution of migrants with respect to Job

\begin{tabular}{|l|l|l|}
\hline Types of job & Frequency & Percent \\
\hline Army & 4 & 5.6 \\
\hline Cashier & 2 & 2.8 \\
\hline Chef & 4 & 5.6 \\
\hline Driver & 13 & 18.3 \\
\hline Manager & 10 & 14.1 \\
\hline Store Keeper & 19 & 26.8 \\
\hline Student & 5 & 7.0 \\
\hline Supervisor & 7 & 9.9 \\
\hline Waiter & 7 & 9.8 \\
\hline Total & 71 & 100.0 \\
\hline
\end{tabular}

Source: Field Survey, 2020

Some of the people have the job on the basis of their skills and some do any kind of jobs for their survival and for study. Most of the migrants were involved in similar type of job which they had in Nepal. Maximum numbers of migrants (26.8\%) were involved as store keeper followed by driver (18.3\%). $14.1 \%$ of them are working as manager in the foreign countries. Most of them (74.6\%) reported that they got their own job according to their skill and almost $85.9 \%$ people were satisfied with the job.

\subsubsection{Arrangement of Money to go abroad}

Majority of migrants i.e. $62 \%$ arranged the money through taking loan and 38\% had arranged through self-finance (Figure 1). 


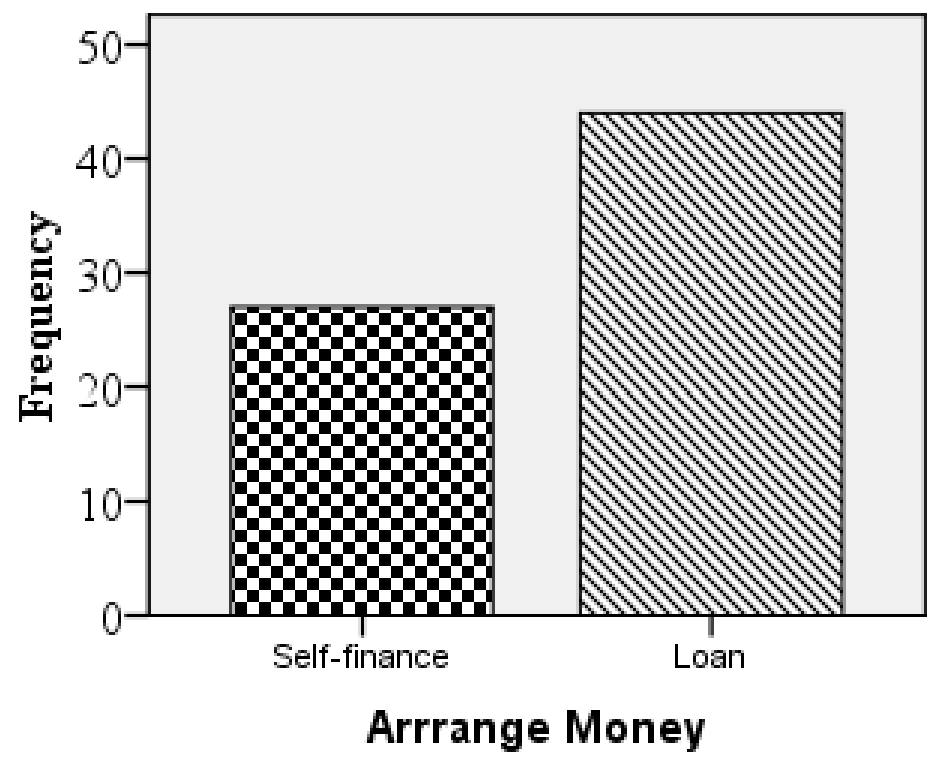

Figure 1: Arrangement of money

\subsubsection{Working per day}

Majority of migrants $45.1 \%$ worked 10 hrs. per day followed by 8 hrs. per day by $22.5 \%$ migrants. Few percent of the migrants worked for 12 to over 12 hours per day. The detail distribution of migrants with the working hour per day has been shown in Table 6.

Table 6: Working hour per day

\begin{tabular}{|l|l|l|}
\hline Time & Frequency & Percent \\
\hline $4 \mathrm{hrs}$ & 12 & 16.9 \\
\hline $8 \mathrm{hrs}$ & 16 & 22.5 \\
\hline $10 \mathrm{hrs}$ & 32 & 45.1 \\
\hline $12 \mathrm{hrs}$ & 2 & 2.8 \\
\hline$>12 \mathrm{hrs}$ & 2 & 2.8 \\
\hline Others & 7 & 9.9 \\
\hline Total & 71 & 100.0 \\
\hline
\end{tabular}

Source: Field Survey, 2020

5.2 Positive and negative impacts to the study area 


\subsubsection{Perception towards positive impacts of migration}

Majority of respondents were found to be positive towards the foreign employment. The most of them reported that increase in their income, improvement of living standard, development of skills, support economic of nation and learn new cultures were the major positive changes caused by migration. $77.46 \%$ of respondents were strongly agreed that after foreign employment, the income was increased. Among all the respondents 56.34\% were positive to the improvement of living standard and learn new cultures.

Table 7: Perception of Respondents towards Positive Impacts

\begin{tabular}{|l|l|l|l|l|l|}
\hline \multirow{2}{*}{ Positive Impacts } & \multicolumn{4}{l}{ Respondent (\%) } \\
\cline { 2 - 7 } & $\begin{array}{l}\text { Strongly } \\
\text { Agree }\end{array}$ & Agree & Neutral & Disagree & $\begin{array}{l}\text { Strongly } \\
\text { disagree }\end{array}$ \\
\hline $\begin{array}{l}\text { Improvement in the living } \\
\text { standard }\end{array}$ & 56.34 & 33.80 & 7.04 & 1.41 & 1.41 \\
\hline Increase Income & 77.46 & 16.90 & 1.41 & 2.82 & 1.41 \\
\hline Opportunity of develop skills & 16.90 & 42.25 & 28.17 & 5.63 & 7.04 \\
\hline Economic support for nation & 1.41 & 14.08 & 77.46 & 1.41 & 5.63 \\
\hline Respect of works & 2.82 & 2.82 & 84.51 & 7.04 & 2.82 \\
\hline Learn new cultures & 56.34 & 33.80 & 5.63 & 2.82 & 1.41 \\
\hline
\end{tabular}

Source: Field Survey, 2020

People of this study area have positive attitude towards foreign employment mainly because of increased income and improvement of living standard. According to the respondent, income has been increased in comparison with past income. Most important things are that migrant's children are getting quality education because of good income from abroad. Almost all of the respondents are involved in their own cultivation of farmland. After the foreign employment, additionally it supports the economic status of the family. Because of this, majority of the people prefer to go to abroad for foreign employment.

Likewise, the other positive impacts are inflow of remittance from foreign countries, experiences, and knowledge on various skills, knowledge about custom, culture, economic and social development about the foreign countries employment. Though the Nepalese are unskilled and poorly educated, they have also got the opportunities to develop their skill, education training, and value of time as well. They can use that skill in their own village and country to raise their income. The remittance money can contribute to develop the 
national economy. Besides, this improved economic status could increase the reputation and prestige in the society.

\subsubsection{Perception towards negative impacts of migration}

Beside the positive impacts it brings lots of negative impacts. The most negative impact of migration was found to be family disorganization that has been strongly reported by $91.55 \%$ respondents followed by changing social role that is $53.52 \%$ and the other is given in Table 17. It can be easily identified from this data analysis that how the migration has affected negatively on society and its various social activities that could lead to the great changes in society.

Table 8: Perception of respondents towards negative impacts

\begin{tabular}{|c|c|c|c|c|c|}
\hline \multirow[t]{2}{*}{ Negative Impacts } & \multicolumn{5}{|c|}{ Respondent (\%) } \\
\hline & $\begin{array}{l}\text { Strongly } \\
\text { Agree }\end{array}$ & Agree & Neutral & Disagree & $\begin{array}{l}\text { Strongly } \\
\text { disagree }\end{array}$ \\
\hline Social Evil & 5.6 & 70.42 & 21.13 & 1.41 & 1.41 \\
\hline Demonstration effect & 2.82 & 78.87 & 11.27 & 7.04 & 0 \\
\hline Changing Social Role & 53.52 & 30.99 & 5.63 & 5.63 & 4.23 \\
\hline Lack of labor Force & 28.17 & 61.97 & 5.63 & 2.82 & 7.04 \\
\hline School dropout & 0 & 0 & 94.37 & 4.23 & 1.41 \\
\hline Family Disorganization & 91.55 & 4.23 & 2.82 & 1.41 & 0 \\
\hline Problem of old age people & 2.82 & 46.48 & 35.21 & 8.45 & 7.04 \\
\hline Negligence of agriculture & 2.82 & 2.82 & 4.23 & 81.69 & 8.45 \\
\hline Higher dependency & 1.41 & 2.82 & 81.69 & 11.27 & 2.82 \\
\hline $\begin{array}{l}\text { Higher expenditure of } \\
\text { consumptions }\end{array}$ & 2.82 & 4.23 & 63.38 & 16.90 & 12.68 \\
\hline
\end{tabular}

Source: Field Survey, 2020

The main negative impact of foreign impact was family disorganization. Migration brings some family problem. The absence of migrants for a long time creates social problem and psychological anxiety. The worst impact of foreign employment is the increasing dependency of the whole family over the earning of a member from foreign labor migration for their households' expenses. The import of cheap goods from outside, readymade garments, shoes and implements have made their life luxurious but in other side it makes 
the people passive also. Likewise, they have a nature of spending more money and adopt urban culture in society. They usually spend the remittance not in the village, but in market centers and town and as a result, the villages remain backward in many aspects. Due to such impacts, the original culture and tradition of the villages are on the verge of extinction. In this way, nowadays the foreign culture is rooted in both urban and rural areas. Most of the youth wants to go the foreign country instead of working in the country. This has further enriched the developed countries and made the developing countries poorer with mass poverty in rural in particular and urban areas in general. Consequently, the emigration of people from the economically active age group might have a negative impact on the society and the country as a whole.

The above analysis shows that the life of the people tends to be better economically after migration only on the basis of food sufficiency, social status, habits and consumption pattern. But this is a phenomenon, which is not going to continue for a long time. The high income generated is because of the economy of destination. It might not be surprising that there might be an end of providing employment possibilities to the Nepalese citizens.

\subsubsection{Change in Agriculture Production}

Almost all of the respondents were involved in agriculture. The agriculture is one of the main occupations of the villagers. According to the survey $62 \%$ respondents, because of the foreign migration there was no change in the agriculture production. Whereas $35.2 \%$ reported that the production has been decreasing and only $2.8 \%$ responded the improvement in production.

Table 9: Effect of the migration on agriculture production

\begin{tabular}{|l|l|l|}
\hline Condition & Frequency & Percent (\%) \\
\hline Increasing & 2 & 2.8 \\
\hline Decreasing & 25 & 35.2 \\
\hline No change & 44 & 62.0 \\
\hline Total & 71 & 100.0 \\
\hline
\end{tabular}

Source: Field Survey, 2020

Absence of human labor is the main reason for the decrease in the agricultural production due to migration of youths to foreign land. While the use of remittance to buy the agricultural land is the reason for the increase in production. In both cases it makes changes in economic condition of the family whether it is positive or negative and this is the one of sociological changes. 


\subsubsection{Causes of Decreasing in Agriculture Production}

The main causes of the decrease in agriculture production in the study areas were the decrease in landholding i.e. reported by $21.1 \%$ people. That may be because of the respondent go to abroad by selling their own land that reduce the land hold size. The other causes were found to be abandoned land and lack of labor.

Table 10: Causes of the decreasing in agriculture production

\begin{tabular}{|l|l|l|}
\hline Causes & Frequency & Percent (\%) \\
\hline Abandoned land & 6 & 8.5 \\
\hline Abandoned land/ lack of labor & 4 & 5.6 \\
\hline Decrease landholding & 15 & 21.1 \\
\hline Lack of labor & 4 & 5.6 \\
\hline No idea & 42 & 59.2 \\
\hline Total & 71 & 100.0 \\
\hline
\end{tabular}

Source: Field Survey, 2020

Migration also effects the agriculture production frequently. Most of the respondent reported that they arrange the money to go abroad by selling agriculture land that reduces the landholding size. That directly decreases the agriculture production. The youth of these villages have extremely inclination to pursue agriculture as their occupation. Moreover, large size of migration of youth for employment and education outside the country has affected agriculture due to the shortage of labor. The cultivated lands are turned into fallows and grazing land. The above reasons are the one which directly or indirectly influence on the economy of the society and in the end the whole society.

\section{Conclusion}

The significance of migration to the economy of Dakshinkali municipality has been growing over time. It has direct and indirect impact on the social aspect as well. Migration has become an important aspect of development because it had helped in enhancing various prerequisites of development such as raising people's standard of living. This study shows that migration is seen as a way to improve both the standard of living and social prestige. Most families use the remittance money to pay back loans because most of them go to abroad by taking loans. After then they spend it on daily consumption including education, health sector and rarely to invest it in productive sector. In most cases, agricultural production was affected as a result of the decreasing of land hold size as well as absence of 
labor. In the case of gender, the participation of male in migration was higher than female. This shows that women are still dependent and bound to the domestic sphere. But in the case of the husbands being away, the wives took the family responsibility and also handled economic matters, thus bringing women out into the public spheres. Thus, it can be concluded that migration has definitely enhanced people's standard of living in relation to better food, clothing, education and income. This improvement has in turn helped them to gain more social prestige.

\section{References}

Bhattarai, P. (2005). Migration of Nepalese Youth for Foreign Employment: Problems and Prospects (A Review of Existing Government Policies and Programmes). S Youth Action Nepal (YOAC), Siphal, Kathmandu, Nepal.

Bhattarai, R. (2007). Open Borders, Closed Citizenships: Nepali Labor Migrants In Delhi.

Bhende, A. and Karmitkar, T. 1998, Principles of Population Studies, Reprint New Delhi: Himalaya Publishing House.

Cox, P.R. (1976). Demography, 5th edition, Cambridge: Cambridge University Press.

David, H.P. 1970: In Voluntary Interational Migration: Adaptation of Retugeers in Bordy (ed), Behaviour is new environment, Adoptation of Magrants Populations. Bevetly Hills, Californica Sage Publication

Gautam, T.R. (2005). Causes and Impact of Migration: A Sociological Study of Emigration from Kandebash, Baglung, and Nepal. Dhaulagiri Journal of Sociology and Anthropology. Vol. 1, pp. 146-163

Gautam, T.R. (2008). Migration and the Problem of Old Age People in Nepal. Dhaulagiri Journal of Sociology and Anthropology. Vol. 2, pp. 145-160

Gurung, S. B., 1973. Causes and impact of migration: Preliminary survey in Surkhet region, Kathmandu, Centre for Economic Development and Administration (CEDA).

Gurung, Y. B. (2008). Migration from Rural Nepal. A Social Exclusion Framework.

Harisiddhi Village profile (2070). Harisiddhi, Lalitpur, Nepal.

Kanskar, B.V.S. (1984): Indo-Nepal Migration: Process and Prospects, Contribution to Nepalese Study, CNAS.

KC, B. K. (1998). Trends, Patterns and Implications of Rural-to-Urban Migration in Nepal, Kathmandu, Nepal.

Khadka, R. B. (1979). Emigration in Nepal: A Micro Level Study of Bayalpata Village Panchayat, A Dissertation Submitted to T.U.

Kumar, B. (2003). Migration, Poverty and Development in Nepal.Asian and Pacific Migration Journal, Vol. 13, No. 2, pp. 205-232.

Nijkamp, P. (2012). Migration Impact Assessment: A Review of Evidence-Based Findings. Review of Economic Analysis, 179-208.

NPC (2003). The Tenth Plan, 2002-2006, Kathmandu, Nepal, National Planning Commission.

Osmolovski, M.B. (2007). Work-Related Migration and Poverty Reduction in Nepal. 
Peterson, W. 1975: Spatial Distribution of Population in Dhading District. A Case Study of Population Distribution in Relation to Fulfillment of Basis Needs, Kathmandu, T.U.

Ravenstein, E.G. (1885). The Law of Migration, Journal of the Royal Statistics Society. Vol.48 (2).

Singh, M. L. (1998). Emigration from Nepal: Some Major Issues, Journal of Population Development, pp 37- 47.

Stalker, P. (1994). The work of strangers: A Survey of International Labor Migration. International Labor Office, Geneva.

Stark and Tailor, (1989). Relative Deprivation and International Migration.

Subedi, B.P. (1991): International Migration in Nepal: Towards an Analytical Frame crone, Contribution to Nepalese Studies, CNAS, Vol. 18, pp. 83 - 98.

Todaro, M.P. (1969). Model of Labor Migration and Urban employment in Less Developed Countries: American Economic Review, Vol.89

Ukwatta, S. (2010). Economics \& Social impacts of the migration of Srilankan transnational domestic worker on families and Children left behind. 